\title{
Bodies (Re) Gained: Gender and Identity in Elif Shafak's Pinhan and Virginia Woolf's Orlando
}

\author{
Begüm Tuğlu
}

\begin{abstract}
The definition of gender has been a source of great controversy. As Michel Foucault argues in The History of Sexuality, since the seventeenth century the Western outlook upon sexuality is rather in the form of suppression due to certain ideological manipulations through the rise of capitalism. This understanding of sexuality was directly connected to one's biological condition which determined whether the individual was a man or a woman, never leaving place for the in between. With this perspective, the repressed society founded upon the sacred bonds of marriage and the institution of family cut out roles for both men and women which defined their gender roles. These roles were mere performances, as Judith butler would argue later on, however, they had great impact upon the formation of identities for a long time. $I$ argue in alliance with critics such as Stuart Hall that the conception of identity does not have an ultimate ending since it constantly transforms, shifts and takes up new meanings along the way. I further assert that gender, as a vital part of identity formation, carries the same essence, however, it cannot be restricted neither to biological nor temporal nor spatial limits. In order to demonstrate the transformative and transgressive stance of gender and identity, I intend to explore how the novels Pinhan (The Mystic) by Elif Shafak and Orlando: A Biography by Virginia Woolf cross the thresholds of time and space. The two androgynous protagonists of the novels express the uniqueness of identity formation in terms of gender in spite of the differing repressive societies they live in. Even though both novels were written by authors from different eras and different cultural backgrounds, they take upon a similar approach to the issue of gender in their own unique ways.
\end{abstract}

Index Terms-Comparative literature, gender, identity, sexuality.

\section{INTRODUCTION}

To claim a place within the symbolic order of society ${ }^{1}$, individuals have long been subjected to many labels, most personal and intimate of which is gender. Social hierarchy bounds individuals to certain alliances with clear-edged definitions of gender, and its roles forced upon them, in order to create a domain which Foucault depicts ever so meticulously in The History of Sexuality. As a social theorist Foucault points out how a society can be controlled through an invisible mechanism of surveillance, creating a culture of fear. Since the individuals living in such a society feel the

Manuscript received April 10, 2016; revised September 3, 2016.

Begüm Tuğlu is with Ege University, Turkey (e-mail: tuglubegum@gmail.com).

"The symbolic order of society" here refers to the theory of Jacques Lacan who claims that once a child enters into the social realm, s/he enters a consensual reality through language itself. Through this linguistic communication the child accepts the laws, ideologies and conventions of the society which gives her/him the power to be able to establish his/her own identity in order to survive (444-5). constant pressure of being watched, they start to act in a certain sense of obedience. A panoptic state needs to integrate each individual into the system to be able to function properly. to achieve this kind of control, it requires the establishment of a symbolic image of a family, which is possible through the strict control of the bodies [1]. Nevertheless, the institution of the sacred family creates certain psychological problems once it is accepted that each individual has a unique process of identity formation. The microcosmic gender of a certain individual turns into an object which the macrocosmic mechanisms of the society can forge according to gender roles The concepts of the father, the mother and the child need to know their places within the system and act accordingly. In parallel, the father needs to perform his masculinity while the mother has to take up different roles at different stages of her life as a woman, whether it be a virgin teenager, a fertile mother, or a seductive mistress. Notwithstanding, it can be asked, what happens if the individuals do not, or rather cannot, perform these roles cut out for them?

\section{SEX, GENDER, ORLANDO AND PINHAN (THE MYSTIC)}

Gender, as a socially constructed concept, has long been identified with one's sex, and directly to her/his biological body whereas the identity formation, as has been argued by many critics such as Judith Butler in "Critically Queer", Julia Kristeva in "Feminine Sexuality" or Jacqueline Rose in "Revolutionary Poetic Language", remains detached from such a constraint. An American historian and sexologist Thomas W. Laqueur in his Making Sex, argues how "[s]ometime in the eighteenth century, sex as we know it was invented", [2]. He further explains how in the depths of the seventeenth and eighteenth centuries science, with a new epistemological discourse, declared two dichotomic categories "'male' and 'female' as opposite and incommensurable biological sexes" [2]. The distinct clarification between the two labels of male and female led to certain rules, which gave the female body the role of reproduction, closely associated with the archetypal connotations of nature whereas the male body was defined as the ultimate power, advocated by Freud and psychoanalysis that "phallus" is the core of all administrations of power and creation. On this issue of female bodies gaining a sociological meaning with the words "man" and "woman", Laqueur further asserts,

As the natural body itself became the gold standard of social discourse, the bodies of women - the perennial otherthus became the battleground for redefining the ancient,

2 emphasis mine 
intimate, fundamental social relation: that of woman to man. Women's bodies in their corporeal, scientifically accessible concreteness, in the very nature of their bones, nerves, and, most important, reproductive organs, came to bear an enormous new weight of meaning. Two sexes, in other words, were invented as a new foundation for gender [2].

Nonetheless, under the light of such critics who exposed this monolithic perspective to be a mere illusion, I intend to explore the characters who transgress this certain definition of gender more intensely. From Shakespearean characters as Viola in Twelfth Night, or Rosalind in As You Like It, to the more contemporary texts as in Virginia Woolf's Orlando, all of whom step ahead of the lines drawn in front of them in terms of gender roles, it can easily traced how the issue of gender is far from being an ultimately defined concept which can be bisected into two distinct halves. Stuart Hall declares that identity is "a construction, a process never completed -always "in process"' [3]. I am also of the same opinion that the issue of gender, being a part of this process, cannot be defined as a de facto concept which denies the existence of unique identities that do not fit into certain labels. In the eighteenth century "men and women were sorted out by the configuration of their bodies [...] into their required procreative and multitudinous other gender-specific roles. The one-sex body of the doctors, profoundly dependent on cultural meanings, served both as the microcosmic screen for macrocosmic, hierarchic order and as the more or less stable sign for an intensely gendered social order" [2]. Nonetheless, in our age it is gradually becoming more apparent that gender itself is a concept which defies the limits of not only biology but also of space and time. I argue that in the novels of Pinhan (The Mystic) by Elif Shafak and Orlando by Virginia Woolf, one can explore the construction of gender and identity with an internalized perspective through the transformation of the body by focusing on time and space.

\section{ORLANDO: A BIOGRAPHY BY VIRGINIA WOOLF AND PINHAN (THE MYSTIC) BY ELIF SHAFAK}

First published in 1928, Orlando is considered to be a semi-biographical novel that implicates the love affair between Virginia Woolf and Vita Sackville-West. The novel focuses on the life of a character who is born a male nobleman during the reign of Elizabeth I, however, wakes up one day to find himself in a female body. One reads how Orlando's path takes her to Constantinople where s/he finds comfort in living, dressing and acting in a rather freer manner than in England. During his/her fantastically long life span of three hundred years and counting, Orlando reveals how one's gender performativity as Judith Butler would call it, can constantly transform regardless of one's sex.

Published in 1997, Pinhan (The Mystic) is the first novel of Elif Shafak which was to be the predecessor of her other novels such as The Bastard of Istanbul, The Forty Rules of Love and The Flea Palace that brought her international fame. Pinhan is the story of a child dervish who is in search of her own true identity. Pinhan, the name of the protagonist, was translated as "the mystic". Nevertheless, I find the translation insufficient in transferring the meaning of the name which is crucially important in understanding the novel. The etymology of Pinhan can be traced back to Persian, in which it carries the meaning "hidden". This seemingly minor detail becomes rather important, since there is something to be hidden in Pinhan's identity. The opening of the novel reveals that Pinhan is "double headed", or in other words, seems to carry the biological features of both sexes, though it is almost always implicitly mentioned in the novel. Pinhan is defined as having two different worlds combined into one feeble body, constantly carrying the weight of having two "souls" simultaneously. What is interesting here is that, in parallel with Orlando, Pinhan also undergoes a transformation from which she wakes up as a woman. Her path also takes her to Constantinople, not to mention that Shafak never allows the readers the ease of knowing what age Pinhan is, since she plays with the concept of time altogether.

Both novels transcend time, space and foremost, the norms of gender since Pinhan and Orlando simultaneously reveal how " $[\mathrm{t}]$ he nature of sex [...] is the result of not biology but of our needs in speaking about it" [2]. Notwithstanding the society's conservative attitude in considering the temporal and spatial reception of the body to be limited, both novels reveal that the unique body and nature of each individual signals a unique identity. Within this frame, I assert that the formation of identity in terms of gender constantly shifts, develops, yet still contains a unity, a totality within itself regardless of any constraints other than personal desires.

\section{ORLANDO, PINHAN AND TEMPORAL TRANSGRESSION}

The first threshold both Orlando and Pinhan, the protagonists whom carry the same name with the titles of the novels transgress is the concept of time. The aging body throughout a one dimensional, linear time zone and its effects upon gender role interpretations has been subjected to various discussions. Nevertheless, "[e]ssentializing discourses in relation to the body need to be replaced by ones that recognize its nature as a social text, something that is both formed and given meaning within culture. The aging body is thus not natural, is not prediscursive, but fashioned within and by culture" [4] which lifts the limitations of time. In this frame, the idea of Orlando, "[t]he brilliant idea of a hermaphrodite time-traveller embodying each great phase of English literature"[5], having a life span which extends from the Elizabethan era to the Victorian period, who does not age according to the linear time, not only assigns the novel itself an element of fantasy but also opens it up for an analysis freed from a diachronic perspective. S/he is in fact, "fashioned" as Twigg puts it [6], according to the requirements of the specific age s/he lives in. During the Elizabethan age, for instance, Orlando finds a much liberal environment in terms of self-representation since the "Virgin Queen" of the age herself carries the qualifications of both sexes as attained by the society. For, "Elizabeth I brilliantly exploited the tensions between her masculine political body and her feminine private body in creating an erotics of court life that both engendered factions of the great men of her realm. [...] She could play the alluring but inaccessible virgin queen and the warrior prince" [2]. Orlando's affectionate relationship with 
Queen Elizabeth, who "refer[s] to herself more often as king, as the nation's husband rather than its virgin mother" [2], portrays this freedom in representing both sexes simultaneously whereas it is apparent that she does not cherish the same opportunity in the highly conservative Victorian age.

"[T]he spirit of the nineteenth century was antipathetic to her in the extreme, and thus it took her and broke her, and she was aware of her defeat at its hands as she had never been before" [6] writes Woolf to depict the suffocating conservative society of Queen Victoria. Nevertheless, Orlando still has to oblige to the certain values of the age, such as marriage. One can read the love life of Orlando throughout the novel up until the Victorian age when Orlando is to be found as a wedded woman. "Woolf's point here is not subtle: the eighteenth century is, for her, fundamentally misogynist and nothing can erase the discomfort Woolf imagines as the eighteenth-century woman's lot" [7]. Her/his body may be subjected to marriage, yet from Woolf's depiction, the reader is ensured that the marriage is still out of the certain ideals of the society and Orlando continues to reject the expectations loaded upon her identity; "She was married, true; but if one's husband was always sailing round Cape Horn, was it marriage? If one liked him, was it marriage? If one liked other people, was it marriage? And finally, if one still wished, more than anything in the whole world, to write poetry, was it marriage? She had her doubts" [6]. Still, no matter how free Orlando tries to act, her motto, "Life! A Lover!" changes into "Life! A Husband!" [6] during the Victorian era, which reveals that even though individuals try to manifest their identities according to their own desires, the external symbolic order finds a way to haunt them. This phenomena raises an interesting question, then. How can one define what sexuality is, if it is not under the sole control of individual and changes throughout time and place? Carol S. Vance attempts to answer this question in her article "Social Construction Theory: Problems in the History of Sexuality". According to Vance, essentialists assumed that "sexuality enjoyed the status of a stable, ongoing, and cohesive entity" [8].

But to the extent that social construction theory grants that sexual acts, identities and even desire are mediated by cultural and historical factors, the object of study - sexuality becomes evanescent and threatens to disappear. If sexuality is constructed differently at each time and place, can we use the term in a comparatively meaningful way? More to the point in lesbian and gay history, have constructionists undermined their own categories? Is there an 'it' to study? [8].

To explore these questions in detail, one can turn to Pinhan, who on the other hand, complicates the situation by completely demolishing the linearity of time with its ambiguous narration span. One can never be sure of the historical period Pinhan actually lives, though it can only be assumed to be around the early 15 th century. This means that Pinhan might have lived during the reign of Mehmed the Conquerer (Fatih Sultan Mehmet); therefore, it would not be far stretched to claim that Pinhan lived in a similar sexually flourishing environment as Orlando. Despite being usually denied by the people of Ottoman Empire, there are certain sources which claim that Sultans' had relationships with younger men ${ }^{3}$. The Sultan's existence is never present in Pinhan, however, it is noteworthy that Pinhan is born into a similar atmosphere and time as Orlando.

What is more is that while binding the traditional Turkish story-telling atmosphere with that of the teachings of Sufism, Shafak attempts to suggest that time is merely an artificial record book on which people dictate their memories. As the Turkish novelist Ahmet Hamdi Tanpınar so mockingly reveals in The Time Regulation Institute, time is but an artificial concept, an illusion. The artificial, distorted time is contrasted with the unification within nature; the difference between past and present melts into the circularity of Pinhan's story. "[T] he two seas spread between the threshold in two distinct colours were actually a single, endless ocean. If this was the way things went, then two hearts could of course meet in a sole body" [9]. This realization of the possibility that Pinhan can unify "two hearts" within one singular body only comes after her/his interaction with Durri Baba (Father Durri) whom functions as a spiritual guide in his quest to find him/herself.

Moreover, the relationship between Pinhan, Durri Baba and the character which stands as the embodiment of love, Yorgaki, not only suggests a bond not so different than the holy trinity, but also reveals an interaction that is not interfered by neither time, nor spatial form. Paul Schilder declares in "The Sociology of the Body-Image" that "identification takes place with persons whom we admire and with whom we are in love [...] the fact that identification is in the unconscious makes it possible to identify oneself with several persons at the same time" [10] which explains Pinhan's love for both Durri Baba and Yorgaki. Nevertheless, "Freud rightly emphasizes that every identification is in the end ambivalent" [10] and Pinhan's initial hesitance in her/his emotions towards this split love, a reflection of her/his own "double-headed", "double-hearted" identity, only forges into one at the end of the novel when s/he wakes up as a woman, being able to embrace both "hearts" and creating a single identity that holds her/him together.

Furthermore, Durri Baba, who is the key figure in adhering the two halves of Pinhan into one, is placed within the story as the archetypal "old, wise man" who leads Pinhan through the labyrinths of her/his own personal story. Even though being depicted as an old man, Durri Baba seems to be detached from the traditional sense of time, being capable of perceiving it as a cyclical, circular concept which enables Pinhan to perceive better her own nature by teaching the wholeness within nature itself. Furthermore, Shafak writes how all literature is born out of "a single dot", which — reminding one of Durri Baba's close relationship with nature and his shifting physical form thanks to this connection - turns into a ring, a cycle; "A dot accelerates/ a dot revolves/ [...] sweet love ends/ the dot transfers itself to a circle/then neither the beginning nor the end/just a common dot.../whatever you name it/whether an apple/or a dot/or memory/ or a circle" $[9]^{4}$. The emphasis put on the symbol of the dot and how it comes to evolve into a cycle also refers to the concept of time itself. Instead of

${ }^{3}$ See Lord Kinross, The Ottoman Centuries: The Rise and Fall of the Turkish Empire, New York: Morrow Quill, 1979.

${ }^{4}$ All translations from Turkish into English are mine. 
perceiving it in a linear manner, Shafak takes temporal issues at hand with a cyclical approach. The cycle turns into a symbol for both Pinhan's unified identity and the concept of time which are both simultaneously whole, and yet, constantly under a transformation.

\section{ORLANDO, PINHAN AND SPATIAL TRANSGRESSION}

Another threshold Orlando and Pinhan transcend hand in hand is space which is interestingly connected to the transformation of their biological bodies. While Orlando travels from England to Turkey, and finds herself/himself at Constantinople, so does Pinhan leaps from a metaphorical door only to find herself/himself at Istanbul. While the selection of the words, Constantinople and Istanbul, by authors one of whom is English and the other Turkish, reveals the Oriental and Occidental perspective of the city, the fact that the city's spatial location is used as a bridge, a door between two different worlds to symbolize the metamorphosis of both Orlando and Pinhan remains the same. It is also worth mentioning that Orlando finds comfort in the Turkish attires, "those Turkish coats and trousers which can be worn indifferently by either sex" [6] which signals the Western outlook upon the East as the embodiment of a woman [11]. Regardless of her personal preferences, it is clear that Orlando feels the urge to fashion her body according to the society s/he lives in. "The voyage from Turkey allows for an extended satirical treatment of the dress and performance of being female, but upon arrival in England, dress pales in relation to the power of the law to determine identity" [12]. This "power of law" forces Orlando to give up the ease s/he feels with the Turkish clothing and turn to the English clothing which declares a clear distinction between the two sexes. The difference between the oriental ease of Turkey and the occidental stress of England in defining the conception of gender also shows itself in the use of pronouns. Instead of having to chose between "he" or "she", the Turkish language offers a neutral pronoun "o" which can be thought as the equivalent of "it". Nevertheless, while "it" cannot be used instead of "he" or "she", "o" can be used neutrally for both men and women without any pejorative connotations. The use of pronouns in addressing individuals could hence be essentially queer. What is more complicated is which pronoun would Orlando prefer if s/he was to be addressed by others? I believe Orlando chooses to act politically when it comes to being a "he" or a "she". S/he fluctuates between one sex to the other in a transgender manner according to the expectations of the society she finds herself in, though it is apparent that the reason why s/he was more comfortable in Constantinople may also be related to this more liberal perception of gender created by neutral pronouns in the language itself.

Pinhan, on the other hand, has never experienced this stress of having to chose to be one or the other, at least not linguistically. S/he rather had problems while defining who he was, primarily with the question "who am I"? In Lacanian terms, once the child enters the mirror stage, through which $\mathrm{s} /$ he becomes aware of his/her own existence and the process of identification with the society, s/he loses the sense of what Lacan calls an "Ideal-I" [13]. While the "Ideal I" is initially the state the child feels complete with her/his surroundings, it later on turns into a specular image in order to adapt into society through linguistic means. These "secondary identifications" or rather "the functions of libidinal normalization" [13] creates a lack within individuals since they can never go back to the bliss they feel before the mirror stage. In order to be able to continue to the process of their identification, individuals need to transform the specular image into their "Ideal-I" in the attempt to fill in the lack created in their formation of identity [13]. In Pinhan's case, Pinhan's "specular image" initially alienates him, yet once $\mathrm{s} /$ he can forge this specular-I into his/her Ideal-I, in which s/he fully accepts his own identity, Pinhan comes to terms with his own body; hence, her/his gender. Pinhan's mirror stage takes place when Durri Baba recognizes, awakens and as the final stage of Pinhan's enterance into the symbolic order, names him; "look at this unseen universe, see yourself. Look at yourself, see the core of all things created. Whose time is due comes, whose time is due goes. Who comes is hidden in who goes; who goes is hidden in who comes" [9]. After Pinhan's epiphany in which s/he realizes the artificiality of the division between human and nature, s/he also realizes the artificiality of the division between the sexes and the gender roles attributed to them. S/he is but a reflection of nature, an embodiment of the universe on a microcosmic level. Once Pinhan awakens to the "truth" as Orlando does right after her/his metamorphosis, s/he takes the name "Pinhan"; "s/he was waiting for a name for ages. And her name awaited her. It is this day that they have reunited. From now on, her name is Pinhan" [9]. Gail Weiss in Body Images writes "the development of an intracorporeal spatiality accomplished through the mirror stage that provides a more positive and productive account of the formation of the body image (and of the I) as an intersubjective phenomenon that need not be grounded in deception" [14]. In parallel with Weiss' argument, once Pinhan transcends the mirror stage, s/he can enter into the symbolic order of "the Neighbourhood of Scorpion Arif", which happens to carry both a masculine name "Scorpion Arif" and a feminine name "Embroiderer Nigar" suggesting a "double-headedness" as Pinhan seems to embody, after carrying out a ritual of cleansing her/his body, a body which Shafak chooses to portray as transforming into a neutral body image.

Orlando's transformation, similar to Pinhan's, comes after he sleeps; thus, makes her/his awakening more than a merely literal one. The exact moment of Orlando's awakening is portrayed with these lines; "[h]e stretched himself. He rose. He stood upright in complete nakedness before us, and while the trumpets pealed Truth! Truth! Truth! we have no choice left but confess--he was a woman" [6]. The emphasis on the word "truth" strikes one as highly important since Woolf painstakingly tries to show one that the biological change of one's body does not change the truth about her/his identity."Woolf, then, leads us to the threshold of culture's haunted mansion not to admonish us to enter; rather, she raises her lamp to help us find our way out of it to trees and sky, 'reality,' [...] Woolf created form after form designed to deliver her readers not to an arrested past, a finished canvas, a text-become-icon, but to that slippery, elusive present" [15], the same slippery foundation Stuart Hall mentions in his 
argument on the constantly shifting nature of human identity. "As Butler argues, the becoming of the subject cannot be described through linear trajectory, but involves disparate series of backward and forward movements in which the subject repetitively, reflexively, turns back upon itself, [...] this self that the subject returns to is not a fixed self' [14]. Accordingly, Woolf writes how Orlando simultaneously holds the qualifications attributed to both sexes by society; "[s]he was man; she was woman; she knew the secrets, shared the weaknesses of each" [6]. It can be seen that Orlando “never feels or suggests 'a woman trapped in a man's body' or 'a man trapped in the body of a woman'. Orlando codes his dress according to practicality or sexual desire" [12].

Hence, where Pinhan is portrayed as being "double headed", Orlando seems to embrace this duality within her/him which actually means that this internalization of duality is more than an acceptance, it is a revelation that, in reality, there is no duality but only a unification, a wholeness in one's identity, as Pinhan realizes at the end of her/his own story. Both characters thus reveal that in terms of gender, "not biology, but culture, becomes destiny"5 [16]. In parallel with this argument, Orlando's affections for Sasha, the Russian princess, does not change with her/his transformation "since the sex change leaves Orlando's identity untouched, the object of her desire is still a woman, the Princess Sasha" [17]. As Monique Wittig states, "[t]he category of sex is the political category that founds society as heterosexual" [18] and as Butler further asserts, "[g]ender norms operate by requiring the embodiment of certain ideals of femininity and masculinity, ones that are almost always related to the idealization of the heterosexual bond" [16]. Sasha "haunts the memory of Orlando the woman as powerfully and pervasively as she dominates the passions of Orlando the man" [19]. Therefore, one can reach to the conclusion that individuals may "act" "the parts of man and woman for ten minutes with great vigour" but they are bound to fall "into natural discourse" eventually [6].

Pinhan's transformation comes rather late compared to Orlando's. However, Pinhan's transformation is a better stance to reveal the unification of sexes in one body since from the very first sentences of the novel it is apparent that having a "double headed" identity remains as a hidden trauma in Pinhan who carries it as a burden upon her/his shoulders. However, this "'splitting' or fragmentation of the subject can be seen as undermining the integrity and agency of the self" [14]. In fact, the name Pinhan literally means "secret", depicting an identity which always considers what s/he carries naturally from birth as a defect, a malformation whereas Scott brilliantly reminds us that "[so]ciology has long discussed sex roles, the term roles calling attention to ${ }^{6}$ the assigned rather than determined nature of gender" [20]. Scott further argues that "[g]ender is" also "a category constructed through cultural and social systems. Unlike sex, it is not a biological fact determined at conception" [20]. Therefore, one can infer that Pinhan's ambigous state of nature, and her/his final biological state of carrying the body of a "woman", has nothing to do with her core identity. Thus,

\footnotetext{
${ }^{5}$ Emphasis mine.
}

${ }^{6}$ Emphasis original.
Pinhan's "chora" as Kristeva defines as the basic instinctual desires, does not, perhaps, cannot change with her bodily transformation. Her/his love for Yorgaki, whose gender is also written by Şafak to give an ambigious state of remaining between the blurry lines of feminine and masculine attributions, will remain the same — which is also valid for the relationship between Orlando and Sasha - since this relationship "refer[s] to the open mesh of possibilities, gaps, overlaps, dissonances and resonances, lapses and excesses of meaning when the constituent elements of anyone's gender, of anyone's sexuality are not made (or can't be made) to signify monolithically" [21] Şafak defines Yorgaki as a carnation, a metaphor reserved in the patriarchal canon of poetry for a feminine identity. His clothing, similar to the ease Orlando feels in Turkish attires, also suggests a manifestation of identity detached from any kind of sexual restraint exposed by clothing; "he had a tufty red belt; and underneath it a loose black baggy trousers. Even this black trousers could not hide the thinness of his legs. Once Pinhan set eyes on this boy made of fire, he could not takes his eyes off of him" [9].

In order to fully comprehend Pinhan's love towards Yorgaki, one can turn to Tim Dean who writes in Beyond Sexuality that "[o]nce we escape an understanding of desire as based on persons, our sexual politics may expand beyond the imaginary diversification and proliferation of sexual norms to which multiculturalism and the critique of identity politics has brought us" [22]. As Butler also argues in "Critically Queer", one can infer that Pinhan "allegorizes heterosexual melancholy, the melancholy by which a masculine gender is formed from the refusal to grieve the masculine as a possibility of love" and "a feminine gender is formed through the incorporative fantasy" [16]. After all, one can read also from Woolf's Orlando that;

The difference between the sexes is, happily, one of great profundity. Clothes are but a symbol of something hid deep beneath [...] Different though the sexes are, they intermix. In every human being a vacillation from one sex to the other takes place, and often it is only the clothes that keep the male or female likeness, while underneath the sex is the very opposite of what it is above. Of the complications and confusions which thus result everyone has had experience" [6].

The reason why both Orlando and Pinhan conclude their respective stories in a female body remains a mystery. Still, one can try to explain this mystery with the fact that the cyclical nature of the female body may better represent the unification of sexes within the formation of the gender identity. Up until her/his awakening with the help of Durri Baba's spiritual guidance which poses a wakeup call, Pinhan remains "neither a woman, nor a man" [11] whereas in Orlando one reads both a man and a woman, as labelled by the Western patriarchal social order, in one body from the very beginning. Nevertheless, in both cases, the protagonists embrace the two sexes within their one biological body as a woman at the end of their respective stories, perhaps for the reasons that Luce Irigaray explains in Sex Which is Not One which leads one to the conclusion that "sexual difference" does not exist. Since the sexuality of a woman is "always at least double, even further: it is plural" [23], completing the cycle of their stories as women stands as the most convenient 
appearance for the two. Pinhan and Orlando, manifest their gender identities without the constraints imposed upon them by gender roles which hints that gender is not related to one's sex, but rather related to their own personal, instinctual desires. As if to justify Simone de Beauvoir's famous claim that "one is not born a woman, but rather becomes one", together Pinhan and Orlando "disdain the loss or partialness implicit in a singular gender identity; [they] refuse the anxious need clearly to define" [12] who they are.

\section{CONCLUSION}

To explain the attempt to achieve a unification of two sexes in body, which directly affects one's gender identity, one is bound to consider the uniqueness of each body that hinders impossible the traditionally accepted labels put on men and women. "[W]hat is required" then, in order to acknowledge the existence of such bodies, "are corporeal solutions, new body images and new ways of imagining bodies whose very diversity resists univocal labels or definitions" [14]. Both Pinhan and Orlando, seem to bring life to "new bodies", cherishing the possibility of a society which embraces its duality — whether it be on the issue of gender or simply starting from the dichotomic perception of the world without the constraints of neither time nor space.

\section{REFERENCES}

[1] M. Foucault, Madness and Civilization: A History of Insanity in the Age of Reason, R. Howard, Trans. New York: Vintage Books, 1988.

[2] T. Laqueur, Making Sex: Body and Gender from the Greeks to Freud, London: Harvard U. P., 1990.

[3] S. Hall, "Who needs 'identity'?" in Identity: A Reader, G. du Paul, J. Evans, \& P. Redman, Eds. London: Sage, 2004, pp. 15-30.

[4] C. Paglia, Sexual Personae, London: Penguin, 1992.

[5] J. Twigg, "The body, gender, and age: Feminist insights in social gerontology," Journal of Aging Studies, vol. 18, pp. 59-73, 2004

[6] V. Woolf, Orlando, Edinburgh: Canongate, 2012.

[7] A. E. Fernald, "A feminist public sphere? Virginia Woolf's revisions of the eighteenth century," Feminist Studies, vol. 31, no. 1, pp. 158-182, Spring, 2005.
[8] C. S. Vance, "Social construction theory: Problems in the history of sexuality," Homosexuality, Which Homosexuality? A. van K. Nierkerk and T. van der Meer, Eds. Amsterdam: An Dekker, 1989, pp. 13-34.

[9] E. Shafak, Pinhan. İstanbul: Doğan, 2009.

[10] P. Schilder, The Image and Appearance of the Human Body, New York: John Wiley \& Sons, 1964.

[11] N. Demirci, "Elif Shafak'ın Pinhan, Araf Ve Mahrem'inde İsim İmgelemi," Turkish Studies, International Periodical for the Languages, Literature and History of Turkish or Turkic, vol. 5, no. 3 , pp. 997-1008, Summer 2010.

[12] N. Cervetti, "In the breeches, petticoats, and pleasures of Orlando," Journal of Modern Literature, vol. 20, no. 2, pp. 165-175, 1996.

[13] J. Lacan, "The mirror stage as formative of the function of the I as revealed in psychoanalytic experience," in Literary Theory: An Anthology, 2nd Edition, J. Rivkin and M. Ryan, Eds. Oxford: Blackwell, 2004, pp. 441-446.

[14] G. Weiss, Body Images: Embodiment as Intercorporeality, London: Routledge, 1999.

[15] C. Froula, "Rewriting genesis: Gender and culture in twentieth-century texts," Tulsa Studies in Women's Literature, vol. 7, no. 2, pp. 197-220, Autumn, 1988.

[16] J. Butler, "Critically queer," in Identity: A Reader, G. du Paul, J. Evans, and P. Redman, Eds. London: Sage, 2004, pp. 108-117.

[17] A. Parkes, "Lesbianism, history, and censorship: The well of loneliness and the suppressed randiness of Virginia Woolf's Orlando," Twentieth Century Literature, vol. 40, no. 4, pp. 434-460, Winter, 1994.

[18] M. Wittig, The Straight Mind and Other Essays, Boston: Beacon Press, 1992.

[19] S. E. Knopp, “'If I saw you would you kiss me?': Sapphism and the subversiveness of Virginia Woolf's Orlando," PMLA, vol. 103, no. 1, pp. 24-34, Jan. 1988.

[20] B. K. Scott, The Gender of Modernism: A Critical Anthology, Indiana University Press: Bloomington, 1990.

[21] E. K. Sedgwick, Tendencies, Durham, NC: Duke UP, 1993.

[22] T. Dean, Beyond Sexuality, Chicago: University of Chicago Press, 2000.

[23] L. Irigaray, The Sex Which is Not One, C. Porter and C. Burke, Trans New York: Cornell U. P., 1985.

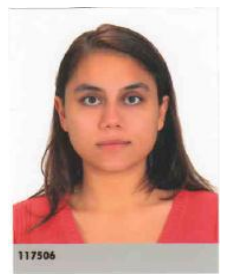

Begüm Tuğlu graduated at the top of her class from Ege University, İzmir, Turkey with a B.A. in English language and literature in 2012. She participated in the LLP/Erasmus Programme in Universita di Bologna, Italy in 2011. She is currently working as a research assistant at English Language and Literature Department of Ege University where she is carrying out her postgraduate studies as a doctoral candidate focusing on Samuel Beckett. She is an editorial assistant at the journal Interactions. Her research interests include modernism, postmodernism, modern English novel, literary theory, cultural studies. 